\title{
Chapter 7 \\ Lowering the Learning Threshold: \\ Multi-Agent-Based Models \\ and Learning Electricity
}

\author{
Pratim Sengupta and Uri Wilensky
}

\section{Introduction}

Electromagnetism, in particular, electricity, is a notoriously hard topic for students at all age levels (Belcher \& Olbert, 2003; Cohen, Eylon, \& Ganiel, 1983; Eylon \& Ganiel, 1990; White, Frederiksen, \& Spoehr, 1993; etc.). The difficulty in understanding basic phenomena such as electric current, electric potential difference (or voltage), electric resistance is often displayed in the novices' explanations involving behavior of simple electrical circuits. Furthermore, misconceptions that stem from these difficulties have been regarded by several researchers as resistant to change due to instruction (Cohen et al., 1983; Hartel, 1982) and indicative of a discontinuity between expert and novice knowledge systems (Chi, Slotta, \& Leauw, 1994; Reiner, Slotta, Chi, \& Resnick, 2000).

Our prior work has shown that the problems faced by novice learners in the domain of electricity can also be understood in terms of the difficulties faced by novices in understanding behaviors of a complex system, i.e., systems in which phenomena at one level emerge from interactions between objects at another level (Sengupta \& Wilensky, 2009; Wilensky \& Resnick, 1999). For example, a traffic jam can be considered an aggregate level phenomenon which arises form simple interactions (such as moving forward, braking) between many individual level agents (i.e., cars). In this chapter, we build on this research and demonstrate how a suite of emergent, multi-agent-based computational models (NIELS: NetLogo Investigations in Electromagnetism; Sengupta \& Wilensky, 2008a, 2008b) can be designed to represent electricity in linear resistive systems in a manner that is intuitive and easily understandable by a wide range of physics novices: from 5th-grade to 12th-grade students.

At the heart of our thesis is the idea that such an emergent perspective enables novices to develop an understanding of electrical conduction by bootstrapping, rather than discarding their intuitive knowledge (Sengupta \& Wilensky, 2009; under

\section{P. Sengupta $(\bowtie)$}

Mind, Matter \& Media Lab, Department of Teaching and Learning, Peabody College, Vanderbilt University, Nashville, TN 37240, USA

e-mail: pratim.sengupta@vanderbilt.edu 
review). NIELS models are based on Drude's microscopic theory of electrical conduction, which presents an emergent picture of electrical conduction. We discuss the epistemic affordances and challenges of Drude's microscopic theory of electrical conduction, specifically in the context of middle and high school learners' development of understanding of electric current as a "rate." We then present a specific NIELS model and show that how it was (re)designed and appropriated to address these challenges for learners 5 th, 7 th, and 12th grades. Finally, we present the effectiveness of our design approach by showing (a) how learners developed understandings and explanations of electric current in linear circuits by coordinating their intuitive knowledge at the agent level through interacting with the relevant NIELS model(s) and (b) how the same NIELS model lent itself to different curricular constraints and epistemological needs of learners in middle school and high school classrooms.

\section{Theoretical Overview: Electricity and the Micro-Macro Link}

\section{Misconceptions in Electricity as "Slippage Between Levels"}

The source of students' difficulties in understanding introductory electricity (i.e., macro-level phenomena such as behavior of electric current in electric circuits) has been explained in terms of a "missing macro micro link" between the domains of electrostatics and electrodynamics (Eylon \& Ganiel, 1990; Sengupta \& Wilensky, 2009; White \& Frederiksen, 1998). This can be explained as follows: Traditional classroom instruction in electricity is typically segregated into two domainselectrostatics and electrodynamics. Electrostatics is the study of how stationary electric charges interact with each other, and electrodynamics is the study of the behavior of moving electric charges in electric and magnetic fields. Studies also show that students find electrostatic interactions between a few charges easy to understand (Cohen et al., 1983; Eylon \& Ganiel, 1990; Frederiksen, White, \& Gutwill, 1998). But introductory concepts in electrodynamics such as electric current, resistance, and potential difference are primarily represented in terms of the symbolic, mathematical derivations of Ohm's law, and the connections with electrostatics are not made explicit during instruction (Eylon \& Ganiel, 1990; Frederiksen, White, \& Gutwill, 1999; Belcher \& Olbert, 2003). Even in laboratory experiments that accompany such theoretical instruction, students typically operate an ammeter and/or a voltmeter (instruments that measure amount of current and voltage, respectively, across a conductor) in a circuit where a wire (resistor) is connected across the two ends of a battery. Therefore, students, after such instruction, are unable to relate behavior of individual charges within the wire at the microscopic level (such as electrons and ions) to the macroscopic level behavior (such as electric current, resistance).

A large body of research has focused on the content and structure of the initial conceptual knowledge of physics novices in the domain of electricity. This work can be summarized as follows: first, research over the past three decades has shown that 
Fig. 7.1 A linear electrical circuit with a single resistor

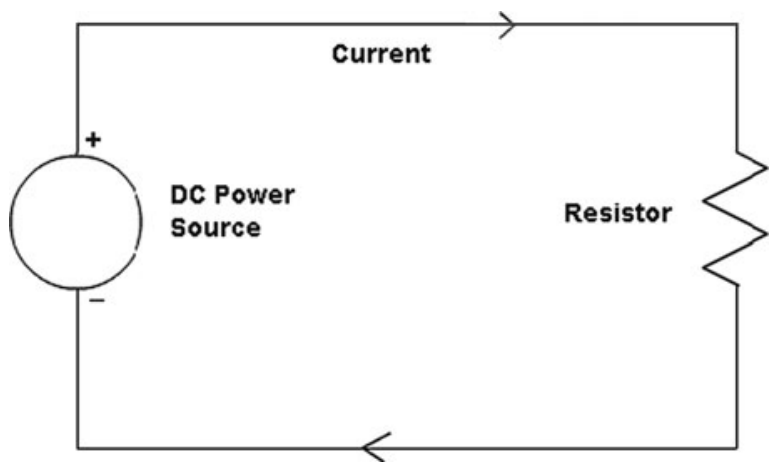

students at all levels - middle school through college-find basic electricity hard to understand (for a review, see Reiner et al., 2000); second, the reason for this difficulty has been predominantly attributed to the incompatibility between naive and expert ontology (Reiner et al., 2000; Slotta \& Chi, 2006; Chi, Slotta, \& Leauw, 1994); and third, although a few researchers have argued for incorporating a microscopic perspective in electromagnetism education, these arguments have been so far limited to advanced high school and college settings and have predominantly used an equation-based approach (Chabay \& Sherwood, 2000; Haertel, 1987, 1982).

Consider, for example, a simple linear circuit shown in Fig. 7.1. Research shows that most novices typically reason that current coming out of the circuit is less than that going in (Reiner et al., 2000). That is, when current coming out of the battery meets the resistor, it slows down and/or some of it is "lost" in overcoming the resistance. This type of reasoning has been termed as "current as an agent" model (White \& Frederiksen, 1992), as well as "sequential reasoning" or the "current wearing out model" (Dupin \& Joshua, 1987; Hartel, 1982).

According to Reiner et al. (2000), these misconceptions indicate that naive conceptual ecology in the domain of electricity is based on a coherent knowledge structure - object schema - that includes ontological attributes of objects such as "being containable," "being pushable," "storable," "having volume" and "mass," "being colored." They argue that experts think of electrical phenomena in terms of "process schemas" (Chi et al., 1994) or "emergent processes" (Chi, 2005; Slotta \& Chi, 2006), and that naive ontology is incompatible with expert ontology. Based on this, Chi and her colleagues argued it is that only by discarding naive ontology that one can engender expertise in novices. They have argued for direct instruction focused on teaching the "process based" or "emergent ontology" (Chi, et al., 1994; Slotta \& Chi, 2006) as the suitable method to teach electricity to novices.

In a recent paper we proposed an alternative cognitive model of naive misconceptions in electricity (Sengupta \& Wilensky, 2009). We argued that commonly noted naive "misconceptions" of electric current and related phenomena can be better understood as behavioral evidences of slippage between levels-i.e., these misconceptions occur when students carry over object-like attributes (e.g., blockage, flow) of the individual agents (e.g., electrons in a wire and charges in battery 
terminals) to the emergent macro-level phenomena (e.g., current). In that paper, we reported results of a pilot implementation of two earlier versions of NIELS models in an undergraduate physics course. In the first model students investigated electrostatic behaviors of two electric charges, and the second model simulated a continuous flow of electrons resulting form an aggregation of electrostatic attractions and repulsions. After interacting with these models, students were able to develop a deep understanding of electrostatics and electric current by "bootstrapping," rather than "discarding" their existing repertoire of intuitive, object-based knowledge. We found that the same object-based, naive knowledge elements that Chi and her colleagues found to be detrimental to learning electricity and incompatible with expert ontology, were, in fact essential components of learners' correct explanations (in the post-test) about electric current and voltage. But, the important difference was that these knowledge elements, instead of being activated only due to macro- or aggregate-level cues (as was evidenced by the participants' pre-test responses), were activated due to micro- or individual-level cues in the post-test. Furthermore, we also found that participants' post-test explanations that involved process schemas at the aggregate-level of description of the phenomena, often involved several object-schemas at the individual level of description of the same phenomena.

\section{The "Emergent" Approach: The Microscopic Theory of Conduction and Its Affordances}

The "emergent" approach toward teaching and learning electricity that we have argued for elsewhere (Sengupta \& Wilensky, 2009; under review; Sengupta, 2009) rests on the microscopic theory of electrical conduction. It was first proposed by the physicist Paul Drude (1900) and is now typically taught at undergraduate and graduate levels (Chabay \& Sherwood, 2000; Ashcroft \& Mermin, 1976). At the heart of Drude's theory is the notion of free electrons, which are the electrons in the outermost shell of a metallic atom (Fig. 7.2). When isolated metallic atoms condense to form a metal, these outermost electrons wander far away from the parent nucleus, and along with other free electrons, form a "sea" or a "gas" of free electrons. The remaining "core" electrons remain bound to the nucleus and form heavy immobile ions. In the absence of an electric field, collisions with these ionic cores give rise to a random motion of the electrons. When an electric field is applied to this "gas" of free electrons, the electrons try to move against the background of heavy immobile ions toward the battery positive. It is the aggregate effect of these electron-ion collisions that give rise to electrical resistance, whereas electric current is the net flow of electrons resulting from the aggregate motion of individual free electrons. The interested reader can find a more detailed qualitative as well as quantitative discussion of Drude's theory in Ashcroft and Mermin (1976; pp. 24-49).

Let us now consider " $n$ " free electrons in a unit volume of a wire, each moving with a velocity " $v$ ". Then, in time $t$, each electron will advance by a distance $v * t$ in the direction of its velocity. So, in time $t$, the number of electrons that will cross a 

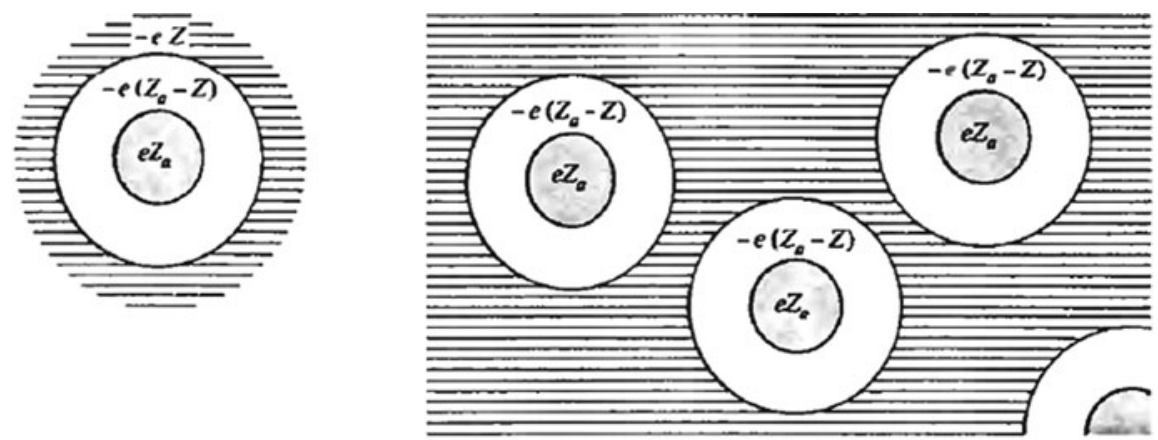

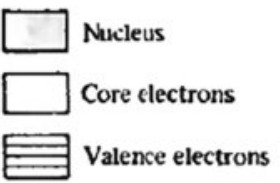

(a)

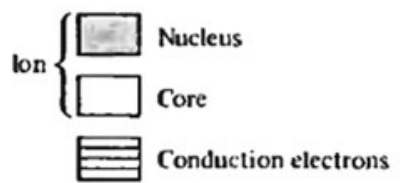

(b)

Fig. 7.2 Diagrammatic representation of free electron theory (Source: Ashcroft \& Mermin, 1976)

unit area perpendicular to the direction of flow would be equal to $n^{*} v^{*} t$. Since each electron carries a charge $e$, the total charge crossing this unit area is equal to $n^{*} e^{*}$ $v * t$. Therefore, electric current (per unit area) can be expressed as

$$
I=\frac{n^{*} e^{*} v^{*} \Delta t}{\Delta t}=n^{*} e^{*} v
$$

Equation 1: Equation for Electric Current

Note that this equation indicates that the two cases of 500 electrons moving at 5 miles per hour and 5 electrons moving at 500 miles per hour will result in the same amount (or value) of electric current. That is, according to this theory, electric current is represented as a rate (i.e., number of electrons flowing per unit time), as well as a quantity that can be conserved under the opposing influences of number and speed of electrons.

We believe that such an approach has the following affordances. First, misconceptions researchers have shown that the constancy of electric current throughout the any linear resistive circuit is one of the most challenging phenomena for students to understand. Following Chabay and Sherwood (2000) and Haertel (1987), we argue that this can be explained using the number-speed balancing mechanism described above. In the circuit shown in Fig. 7.1, while there is a higher concentration of free electrons in the wire, they are moving slower due to lower voltage; whereas, in the resistor, there are fewer electrons that are moving faster toward the battery positive. This in turn can be understood in terms of inherent properties of conductors and resistors - usually a material with a higher resistance possesses a higher density of obstacles to electron flow, and/or it offers a smaller concentration of free 
electrons. Both effects normally appear together within a resistor and can cause a dramatic change in mobility for the electrons (Chabay \& Sherwood, 2000; Haertel, 1987). Note that the generativity of this model of electrical conduction lies in the fact that the same mechanism - "balancing" electric current due to the simultaneous and complementary changes in the number and speed of free electrons-can explain why electric current in a series circuit remains constant throughout the circuit, even when the component wires or resistors in the circuit have different amounts of resistance.

Second, we believe that such a mechanism is intuitive for novices and thus can provide them with a sense-of-mechanism for understanding how electric circuits work. The construct "Sense-of-mechanism" (diSessa, 1993) can be understood as schematic knowledge structures, which, upon activation, provide learners with the following capabilities: (a) to assess the likelihood of various events based on generalizations of what does and does not happen; (b) to make predictions and post dictions; and (c) to provide causal descriptions and explanations-for example, once activated, they can justify various proportionalities that are embodied in the representation of the relevant phenomena. diSessa and colleagues (diSessa \& Sherin, 1998; diSessa, 1993; Hammer, 1996) argue that a rich system of knowledge elements that are organized only to a limited degree, makes up the naïve physical sense-of-mechanism and are called phenomenological primitives or p-prims. P-prims are hypothetical knowledge structures (such as the "balancing" p-prim: equal and opposing influences cancel each other) and usually abstracted from common experiences (e.g., balancing with seesaws and weights).

We believe that learners' interactions with NIELS models can activate such productive and intuitive knowledge elements in their minds. For example, the effect of voltage on free electrons is represented in the NIELS models in terms of a combination of "push" and "pull"; resistance is represented in terms of "collisions" or "bouncing"; electric current is represented as a "flow" as well as a process of "filling up." Note that each of these actions (push, pull) or mechanisms (e.g., bouncing, collisions) is intuitive and can be easily understood by novices, and they have also been regarded as body syntonic (Papert, 1980). We believe that based on these simple rules, students can then (a) generate higher level mechanisms that simulate equilibration processes - such as the equality of electric current for complementary sets of values of number and effective speed of electrons toward the battery positive; and (b) explain macro-level observable phenomena such as behaviors of series and parallel circuits, how light bulbs work.

\section{Potential Design Challenges from a Developmental Perspective}

A central design challenge for the present study is posed by the differences in the prior learning experiences (primarily curricular) about rates, among fifth and seventh graders on one hand, and 12th graders on the other. In the middle school where NIELS was implemented, "rates" are introduced to students in the latter half of the seventh-grade academic year in their math classes. Therefore, at the time when 
NIELS was introduced to them, neither fifth nor seventh-grade participants had studied rates before. On the other hand, 12th graders were already very familiar with "rates", as a part of their regular math and science curricula. This suggested that understanding electric current as the "rate" of electron flow might be easy for 12th graders, but might prove to be challenging for fifth and seventh graders.

Furthermore, previous research suggests that novices face difficulty when presented with the task of discriminating between conflicting predictions. For example, Inhelder and Piaget (1958) and Siegler (1976, 1981) documented such a stage in the development of children's understanding about the balance beam, and they also documented analogous developmental sequences in other domains (e.g., volume conservation). Let us consider a balance beam or a seesaw. If a weight is placed on each side of the fulcrum, the beam will either tilt counterclockwise, tilt clockwise, or not tilt at all. The effectiveness of a weight in causing the beam to tip is determined by the product of the weight $(w)$ and its distance from the fulcrum $(d)$, a construct called the torque associated with the weight. If the total torque associated with the weights on each side of the beam is the same, the beam will balance; otherwise, the beam will tip to the side with the greater torque. This rule has been termed in the literature as the "product-moment rule" (Hardiman, Pollatesk, \& Well, 1984). Piaget found that in reasoning about this task, initially children focus only on weight of the objects placed on either end of the beam. Eventually, Piaget found that by age 14 , children develop the ability to coordinate weight and distance in the balance beam problem. In fact, studies have revealed that across several experiments, only $20 \%$ of adults have produced responses to balance beam problems consistent with the product-moment rule (Jackson, 1965; Lovell, 1961; Siegler, 1976).

In a similar sense, we hypothesized that the effect of simultaneous and complementary co-variation in number and speed of electrons may be difficult for younger students (fifth and seventh graders) to understand. This is because focusing on either of the variables (instead of both of them at the same time), under certain conditions, might lead to contradictory predictions. For example, while a higher number of electrons may lead to higher current, lower speed of electrons would lead to lower current. If a situation involves both these conditions occurring at the same time, then students might face challenges in making predictions. However, our goal here is to show specifically how to address this issue through redesigning the NIELS Current in a Wire model.

\section{Lowering the Threshold for Learning: Designing NIELS to Leverage Naïve Intuition}

\section{NetLogo: A “Glass-Box” Platform for Learning and Modeling}

NetLogo (Wilensky, 1999a) originated in a blend of StarLisp (Lasser \& Omohundro, 1986) and Logo (Papert, 1980). From Logo, NetLogo inherits the protean "turtle." In traditional Logo, the programmer controls a single turtle, while a NetLogo 
model can have thousands of them. The phrase "glass-box" indicates that the underlying NetLogo code that generates each NetLogo model is always accessible to the learner, and more importantly, the NetLogo programming language is designed specifically so that novices can easily understand and modify it. From the low-threshold side, this enables novices not only to examine and modify the assumptions and rules that generate the model, but also interpret the mechanism(s) depicted in the models in terms of these simple rules of interaction between the agents that are mostly body-synctonic, instead of having to resort to the formalism of equational representations. And on the high-ceiling side, by enabling learners to modify and expand the model that they are provided with, it enables them to dive deeper into the content, as well as explore, investigate, and build models of more advanced phenomena that are typically taught in more advanced levels.

NetLogo is in widespread use in both educational and research contexts, and a variety of curricula have been embedded in the NetLogo environment. Typically, in curricula using multi-agent models (e.g., GasLab (Wilensky, 1999b), EACH (Centola, McKenzie, \& Wilensky, 2000), Connected Chemistry (Steiff \& Wilensky, 2003; Levy \& Wilensky, 2009), BEAGLE (Rand, Novak, \& Wilensky, 2007)), students begin by exploring the behavior of pre-built simulations designed to focus on some target concepts. They make predictions about the behavior of the model under varying model parameters and then test their predictions by exploring model outcomes as they manipulate variables in a simple graphical user interface. Students, however, at any time may open up the "black box" of the dynamic visualization interface and examine as well as modify the underlying rules that control the individual elements of the model. NIELS consists of several such pre-built models designed for teaching target concepts in electromagnetism. Although students can also examine and alter the NetLogo program that governs behavior of the individual agents by opening up the procedures window, and studies have shown that novices and young learners can indeed learn to modify and program NetLogo models (Blikstein \& Wilensky, 2008; Wilensky, Hazzard, \& Longenecker, 2000), participants in this study were not required to modify the underlying code.

The core of every NetLogo model is the interface window (see Fig. 7.3). Typically, the interface contains a graphics window, a plotting window, and several variables in the form of sliders and buttons that students can manipulate. It is here in the interface window that students can observe directly the interaction between the macro-level phenomenon and micro-level agents. The plotting window(s) enables students to observe the effects of their manipulations of the system on macroscopic variables, and the graphics window presents a visualization of the emergent behavior. These sources of feedback enable students to receive instant feedback about their predictions as they interact with the system by modifying system parameters. Each model also contains an information window that contains a description of the content underlying the model, instructions on how to use the interface window, and some suggested extensions or modifications of the NetLogo procedures. 


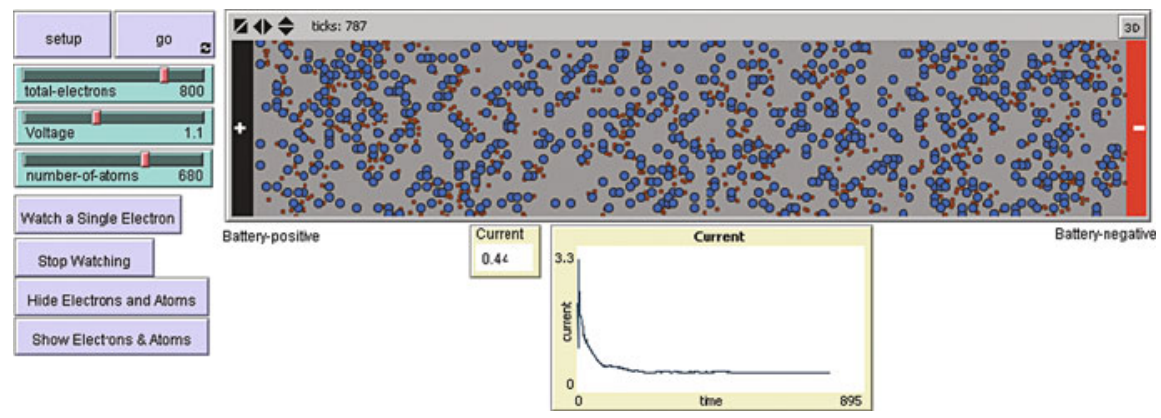

Fig. 7.3 NIELS “current in a wire" model

\section{The Original Model: Electric Current in a Wire}

This model (Sengupta \& Wilensky, 2008d) illustrates how a steady electric current and resistance emerge from simple interactions between the free electrons and atoms (ionic cores) that constitute the electric circuit. It shows how the proportionality based relationships between current $(I)$, resistance $(R)$, and voltage $(V)$ emerge due to the interactions between individual electrons and atoms in the wire. According to Drude's theory, in the presence of an externally applied electric field, each electron is accelerated till it suffers collisions with an atom. As a result of this collision, in our model, the electron loses its velocity and scatters, and again has to accelerate from a new initial velocity of 0 , immediately after the collision.

The variables in this model are total number of free electrons (total electrons), voltage, and number-of-atoms. Additionally, students can also "watch" an individual electron, as well as "hide" the electrons and atoms from their view without affecting the underlying rules of interaction between them, so that they can focus only on the trajectories of individual electrons. The graph displayed in the model plots the instantaneous current vs. time by calculating how many electrons are arriving at the battery positive per unit time.

\section{The Redesigned Model: Electron-Sink Model}

This model, shown in Fig. 7.4, (Sengupta \& Wilensky, 2008c) is a simplified, as well as modified version of the previous model. While the previous model is aimed at focusing the learner's attention on the process of movement of free electrons inside the wire, the goal of this model is to frame the motion of electrons in terms of a process of "Accumulation" inside the battery positive in order to help fifth and seventh graders understand the notion of electric current as a "rate" in an intuitive fashion. Based on the literature in multiplicative reasoning (Thompson, 1994; Kaput \& West, 1994), our hypothesis was that such a reframing would enable students as young as fifth graders to interpret electric current in terms of how fast 

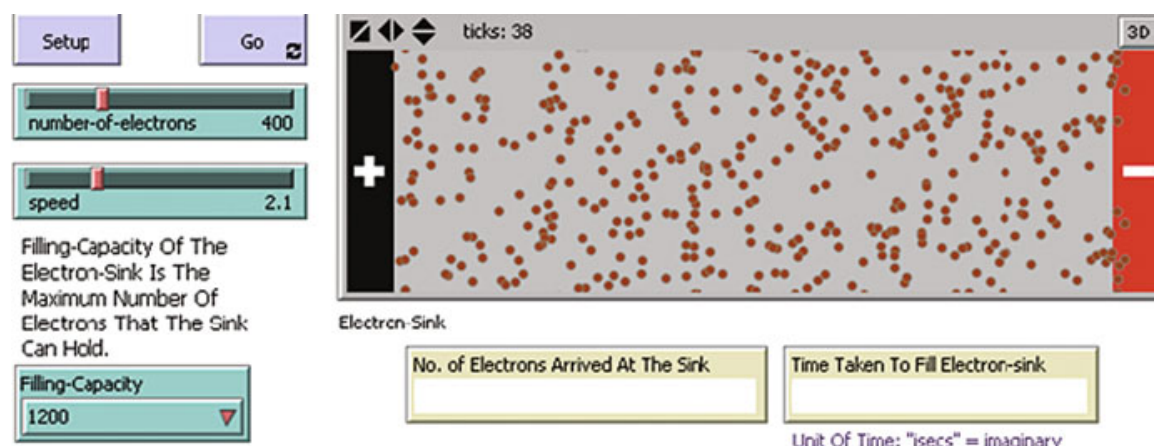

Electren-Sink
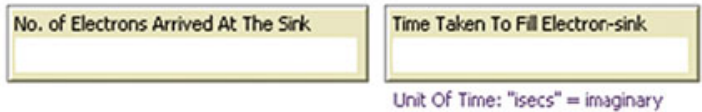

Unit Of Time
seconds

Fig. 7.4 NIELS electron-sink model

the electron-sink fills up-a qualitative and comparatively more primitive form of "rate" based understanding, which in turn can be further developed onto a more formal understanding of rate through scaffolding in successive models, as we show later.

In contrast to the Current in a Wire model, the electron-sink model therefore has only two variables: number and speed of electrons. The variables, voltage and resistance, that were present in the first model were condensed into a single variable, represented by the "speed" of electrons toward the battery positive. Another difference is that the atoms are also hidden from view. This was done so that students could focus on understanding the effects of the speed of electrons, as opposed focusing on the factors that control speed.

The battery terminals are represented as "electron-source" and "electron-sink" in the user interface of the models, as well as in the activity sheets. This was done in the hope that students would tap into the semantic schemas of the terms "source" and "sink" and use them to interpret the functions of the battery terminals. Finally, a third variable, "electron-sink capacity", was introduced into the model. The function of this variable is to stop the model once a certain number of electrons reach the battery positive, and a "monitor" (see the right-hand side in Fig. 7.2) displays the "time taken to fill the electron-sink" $\left(T_{\mathrm{S}}\right)$. In terms of situational semantics, together with the "source-sink" metaphor, this creates an overall context of "containment", in which the electron-sink can be conceived of as a reservoir or a container that in which electrons are "building up" in number.

\section{The Study: Setting, Method, and Data}

The research design is a mixed method, quasi-experimental study, including both clinical interviews and quantitative analyses. It is important to note that the comparison between groups presented here was not planned a priori as a controlled study. Rather, the goal of the analysis presented here is to highlight some interesting 
differences in terms of the learning experiences and learning outcomes among different groups of students, when each group of students used somewhat different versions of the same model. One group of students consisted of fifth and seventh graders (one section in each grade) who interacted with the NIELS Current in a Wire model (see Model B in Fig. 7.5) and is referred to here as the Pilot group. Another group consisted of fifth- and seventh-grade students (one section in each grade), who interacted with the electron-sink model, and are referred to here as the electron-sink group (see Model A in Fig. 7.5). And finally, the performances of both these groups are compared to another group of 12th-grade students who interacted with the Current In A Wire model (see Model C in Fig. 7.5). Screenshots of the user interfaces of each model are shown below in Fig. 7.5, and the differences between the models used by each group are also discussed in a following section. The activities performed by students in the different groups are shown in the Table 7.1.

It is important to note that in activity D, students in the electron-sink group were presented with a definition of electric current in terms of the activities that had just carried out-i.e., in terms of a process of accumulation of electrons inside the battery positive. In contrast, neither students in the Pilot group (fifth and seventh grade) nor 12th graders were presented with an explicit definition of electric current. Also, the process of electrical conduction depicted in the Current in a Wire model was not explicitly framed in terms of accumulation inside the battery positive. Instead, they constructed their understanding of electric current through reflecting on how each of the individual variables, such as number of electrons, voltage, and number of atoms, were related to the value of electric current.

We present two types of analysis:

(a) First, we present an analysis of explanations of students (fifth and seventh graders) who were part of the NIELS 2008 implementation and interacted with the electron-sink model. After performing the "Balancing Filling-time" activity (see activity $\mathrm{C}$ in the table above), students were asked to explain why they think "filling-time" was identical in both cases. The second explanation was solicited immediately after this when participants were asked to explain how they would measure electric current based on the activities they performed thus far (see activity D in the table above). The data presented here consist of (a) semi-clinical interviews conducted with participants in the electron-sink group while they were conducting the "Balancing Filling-time" task (see activity C in Table 7.1) and (b) their written responses of both the activities.

(b) In order to assess the "efficacy" of the electron-sink model, we compared the performance of students in all the groups on a particular task, in which they were asked to predict (and explain) whether electric current would be equal, higher, or lower if twice as many electrons moved twice as slowly (see activity D (Pilot Group) and activity E (electron-sink group) in the table above). The data for this task are entirely based on participant's written responses.

During these implementations, students interacted with the NIELS models in randomly assigned groups of two or three, and the same group composition was 


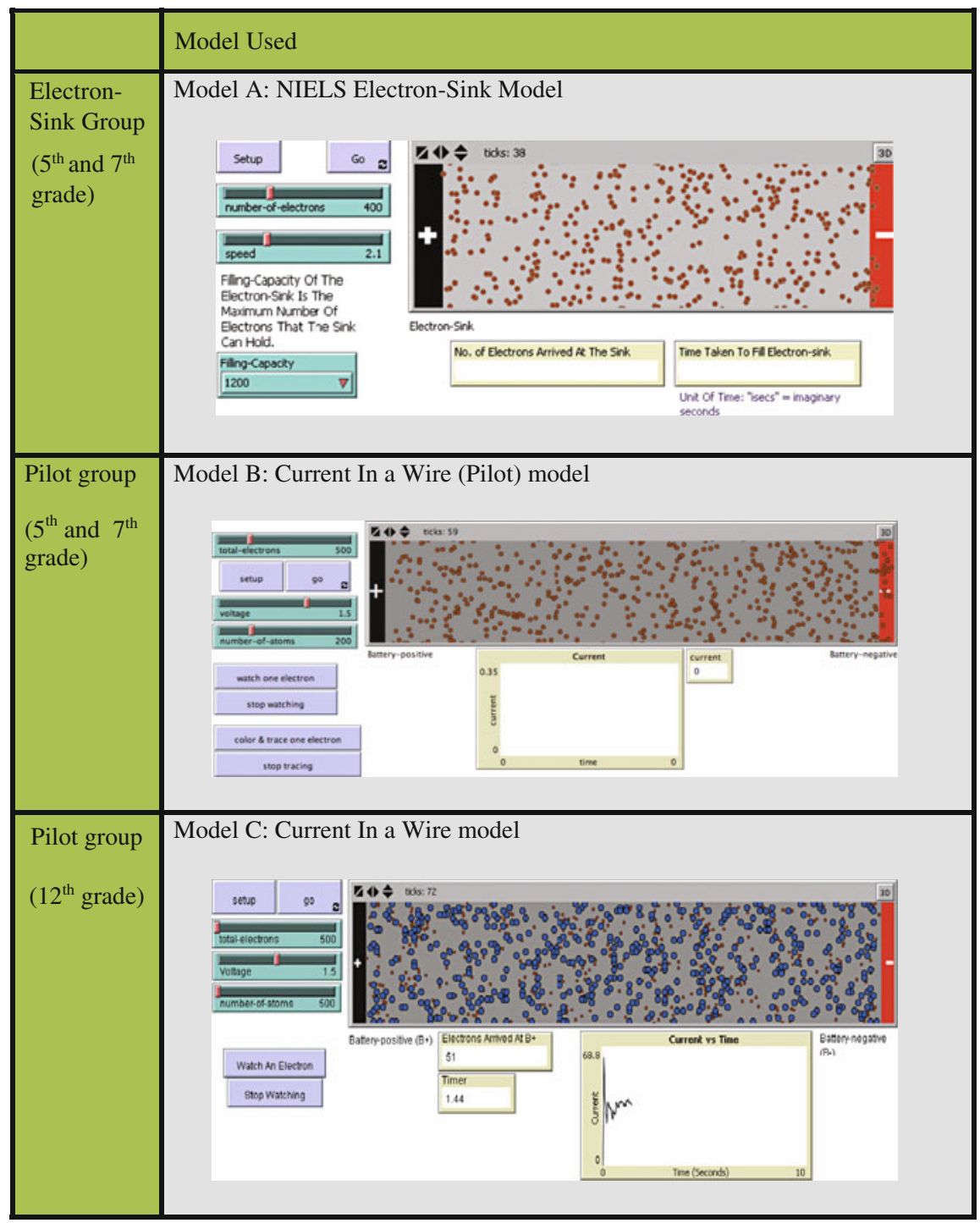

Fig. 7.5 User interface of NIELS models used by different groups

maintained throughout the length of the implementation. Each NIELS model is accompanied by activity sheets that contain some relevant content knowledge (such as a multiple-analogy-based introduction to free-electron theory, descriptions of "variables" and other functional features of the model's user interface) as well as instructions to guide students' interactions with the model. Students were also required to log their observations and describe them in detail in these sheets. The activity sheets also contain frequent prompts for reflection in which students are often asked to provide detailed mechanistic reasoning of relevant phenomena. Each 
Table 7.1 Learning activities performed by pilot and electron-sink groups

Pilot group

(A) Change only the value of number of electrons

a. Predict how and why electric current would change.

b. Observe (and compare with prediction) the effect of this alteration on electric current.

Additional activity for 12th graders only: Draw a graph of current vs. number of electrons and identify the equation that best describes their relationship. (A list of possible equational relationships, based on proportionality, was provided to them)

(B) Change only the effective speed of electrons toward the battery positive by controlling voltage, and

a. Predict (and explain), the effect of this alteration on electric current.

b. Observe (and compare with prediction) the effect of this alteration on electric current.

Additional activity for 12th graders only: Draw a graph of current vs. voltage and identify the equation that best describes their relationship. (A list of possible equational relationships, based on proportionality, was provided to them.)

(C) Change only the effective speed of electrons toward the battery positive by controlling number-of-atoms, and

a. Predict (and explain) the effect of this alteration on electric current.

b. Observe (and compare with prediction) the effect of this alteration on electric current.

Additional activity for 12th graders only: Draw a graph of current vs. number-of-atoms and identify the equation that best describes their relationship. (A list of possible equational relationships, based on proportionality, was provided to them)

(D) Explain whether electric current would be equal, higher or lower, if twice as many electrons moved twice as slowly.
Electron-sink group

(A) Change only the number of electrons

a. Predict, along with mechanistic explanations how the "filling-time" $(T)$ would be affected.

b. Observe (and compare with prediction) how $T$ is affected.

(B) Change only the speed of electrons and observe how $\mathrm{T}$ depends on it;

a. Predict, along with mechanistic explanations how $T$ would be affected;

b. Observe (and compare with prediction) how $T$ is affected;

(C) Find two widely different sets of values of number and speed for which $\mathrm{T}$ is identical.

a. Why do you think the electron-sink filled up in the same time $(T)$ in the two cases? Explain your answer in detail.

(D) Given that electric current can be defined as "how fast the sink fills up," how would you measure electric current in the model?

(E) Explain, if electric current would be equal, higher or lower, if twice as many electrons moved twice as slowly.

section consisted of 20 students. Note that the interventions reported in this chapter lasted one class period in each grade, and each period lasted $45 \mathrm{~min}$.

The data for this study comes in two forms-semi-clinical interviews and written explanations. I conducted semi-clinical interviews with randomly selected four students in each class while they were interacting with the models. In these 
interviews, which were videotaped, students were asked to provide mechanistic explanations of relevant phenomena and I would often ask questions to clarify and/or disambiguate parts of their responses.

\section{Differences Between the Models Used}

There are three main differences between the electron-sink model (also referred to as model A in Fig. 7.5) on one hand, and the two versions of the Current in a Wire model (i.e., models B and C in Fig. 7.5) on the other. The first difference lies in the "framing" of motion of electrons as a process of accumulation inside the battery positive in model A. While all the models depict motion of electrons inside the wire, model A has additional constraints (e.g., maximum filling-capacity) and linguistic cues (e.g., battery positive is referred to as "electron-sink") that are specifically intended to enable learners to focus on the process of charge accumulation inside the battery positive and to conceive of electric current as how fast the electron-sink is filling up. The second difference among the models pertains to the representation of resistance in both the models. Note that neither model displays "atoms". Model B, however, has a variable "number of atoms", by controlling which one can alter the probability of collisions of electrons with atoms, which effectively alters the speed of each electron toward the battery positive. In model A, students control the speed of electrons toward the battery positive through the variable "speed," and there is no mention of any "mechanism" (such as collisions with atoms) through which the speed is affected. The third difference lies in the fact that electron-sink model does not display the value of electric current or the current vs. time graph, whereas both of these are present in models B and C.

There is also one difference between models B and C. While both these models involve collisions between electrons and atoms as the "mechanism" of resistance, in model $\mathrm{C}$, the atoms that act as hindrances to the electrons are visible to the learner, and the resistance can be controlled by controlling the number of atoms. In model B, the atoms are not visible to the learner; instead by controlling the number-of-atoms, they can control the probability of electrons experiencing collisions as they move toward the battery positive. Note that the learning activities performed by the pilot group students (who interacted with model B) and the 12th graders (who interacted with model C), as listed in Table 7.1, do not leverage this difference between the models, and we therefore believe that this does not present any significant confound to the study reported in this chapter.

\section{Coding and Analysis}

Throughout the studies reported here, we use the following "constructs" in order to classify learners' knowledge: registrations, causal schemas, and phenomenological primitives or p-prims. 


\section{Registration}

As stated in Sengupta (2009), and building on Roschelle (1991) and Lee and Sherin (2006), we define registrations as the representational structures embodied in the user interface of the NIELS models that are made selectively salient and potentially meaningful during the course of an interpretive action by the learner. Registrations, in the sense we use it in this chapter, indicate how learners parse the phenomena represented in the models through focusing on certain model attributes that are salient to them. Typically, registrations were identified in participants' responses to the following interview questions: "what's going on in the model?" or "can you explain to me what you are currently doing?" Similarly, in the activity sheets, participants were often asked to describe what they were observing in the model as a result of changing particular variables in the model, or for particular configurations of the model's variables.

For example, if the movement of electrons register in the learners' minds as a process of accumulation inside the battery positive, learners can then be prompted to think about in the factors on which rate at which the electron-sink is filling up depends on-i.e., both the number and speed of electrons. Learners can then be prompted to think about electric current as how fast the battery positive is filling up with electrons.

\section{Causal Schema}

Following Forbus and Gentner (1986), we define causal schemas as binary relations among variables. It is a weak form of a concept-i.e., the mechanisms represented in causal schemas are often not elaborated. However, the coordination of several different causal schemas can lead to a more detailed explanation or interpretation of a "mechanism" or a "process."

Causal schemas were identified based on learners' written or verbal explanations when participants would often be asked to explain the effect of changing particular variables. An example of a casual schema pertaining to the electron-sink model is "higher speed [of electrons inside the wire] leads to a lower value of the "fillingtime." Here, "higher speed" is the causal agent, and "lower filling-time" is the result, and in such cases, the coding as performed by identifying the relevant causal agents and relationships between them in students' written or verbal responses.

\section{Phenomenological Primitives}

P-prims or phenomenological primitives are hypothetical knowledge structures that are abstracted form our early experiences with the physical world. These are more "generalized" and "abstract" than causal schemas (which are rather situationspecific), and are activated upon being recognized due to familiar contextual cues. An example of a p-prim particularly relevant to this study is cancelling (diSessa, 1993). diSessa points out that this p-prim is activated in situations in which two opposing forces "try" to achieve mutually exclusive results but happen to cancel each other out. diSessa (1993) writes: "Canceling is likely a common abstraction for 
many cases of joint, although not necessarily simultaneous, application of "equal and opposite" tendencies. For a situation involving dynamic balancing, canceling justifies lack of result" (diSessa, 1993, p. 135).

Note that the important difference between causal schemas and p-prims is that causal schemas are more directly model-based, whereas p-prims are comparatively more abstract hypothetical knowledge structures. For example, the "blockage" causal schema expresses a relationship between a higher number of atoms and the difficulty of movement of electrons-i.e., more blockage means more travel time for electrons. This is model-based, as it directly expresses a relationship between two entities in the model. On the other hand, the dynamic balance p-prim is comparatively more abstract, in the sense that is domain general-diSessa (1993) argue that this p-prim can be applied to explain several situations across domains that involve the action of two opposing forces or directed influences.

\section{Findings}

\section{Mental Models of Students in the Electron-Sink Group (Fifth and Seventh Grade): Understanding Conservation of "Filling-Time"}

The data for this section comes from interviews with four students in each grade in the electron-sink group, as they were interacting with the model and performing activity $\mathrm{C}$ mentioned in Table 7.1. As scaffolded by the sequence of activities $\mathrm{A}$ and B as listed in section Table 7.1, students typically started out by observing how number and speed of electrons, when varied separately, affect the value of "fillingtime" (i.e., how long it takes for the sink to fill up). I present here the analysis of two sample interviews that are representative of the entire corpus of eight. Of these, one interview is with a fifth-grade student and the other is with a seventh grader. These interviews reveal how a particular type of registration-i.e., students' mental construal of charge flow as a building-up process inside the battery terminal enabled them to identify a mechanism (e.g., compensation, or balancing) through which both the number and speed of electrons simultaneously affect electric current. These interviews, as evidenced in the sections below, then bring to light how students come to coordinate the number- and speed-based causal schemas in order to explain how the value of filling-time can be conserved, through using the "dynamic balance" or "cancelling" p-prim.

\section{Amber (fifth grade)}

This excerpt indicates that the student Amber was able to identify that the fillingtime $(T)$ is inversely proportional to the speed of the electrons. In lines 2 and 4 , she explained that her "theory" was that as electrons have higher speed, more of them get into the battery positive and occupy more and more room, which thereby reduces the filing time. Lines 4 and 6, however, also indicate that the learner was changing 
Excerpt 1:

Interviewer (Int): So what is going on in this model?

1. AMBER: when you increase the speed, ummm.. more negatives go to the positive umm.. and probably make more electricity

2. Int: And the time (pointing to the monitor displaying $T_{s}$ on the computer screen)..? what happens to the time?

3. AMBER: well.. the time goes down.. I have a theory that since it (electrons) is going so fast, it takes up more and more room (inside the electron-sink).

4. Int: since "it" is going so fast? (urging Amber to continue her explanation)

5. AMBER: since it is going so fast, it takes up more and more room and so less time to fill it up (points to the electron-sink on the screen)

her spatial perspective from being inside the wire to being inside the electron-sink. For example, the phrase "it is going so fast" in line 5 refers to an electron moving inside the wire, while the phrase "it takes up more and more room" in line 6 refers to how the electrons are filling up the electron-sink by occupying incrementally more "room" inside the battery terminal. So, the motion of electrons, once they enter the positive terminal, registered in the student's mind as a form of accumulation (i.e., a building-up process).

In the following excerpt, Amber explains how she got the value of $T$ to be equal for two different sets of values of the number and speed of electrons.

\section{Excerpt 2:}

1. Int: so can you explain how you did the value of time to be equal in both cases?

2. AMBER: what do you mean?

3. Int: I mean... the number (of electrons) here increased, and the speed decreased, right?

4. AMBER: right..

5. Int: but you still get the same time, right?

6. AMBER: right

7. Int: how is that happening?

8. AMBER: well because you are taking off the 800 to get 500, and because you are taking off from one number, then you have to add to another number. like $4+3$.. if you take 2 out of 4 , then you have to put that two back on to 3 ... so it would be $2+5$, and that would be the same thing as $4+3 \ldots$ so that is what basically what we did...

9. Int: OK.. so that was a really nice explanation.. so could you explain that in terms of the wire and the electrons?

10. AMBER: So.. umm.. for the electrons.. you had to decrease their number, and umm.. the speed.... umm.. you had to increase, to make up for the time...

Amber's explanation here is based on the following: (a) causal schemas that involve number and speed of electrons as individual causal agents, individually affecting the value of $T$; and (b) a coordination of these causal schemas, i.e., simultaneous and mutually compensatory change in both the number of electrons and their speed, that can conserve of the value of $T$. Amber's observations (as a part of activities $A$ and $B$ as shown in Table 7.1), in the form of written responses, indicate that she was able to identify that number and speed, when varied individually, affected how fast the sink was filling up. In line 8 , she explains how by changing both these 
causal agents, when simultaneously, results in keeping the value of the filling-time (T) unchanged. To do so, she uses the following metaphor: in order to keep the sum $(S)$ of the two numbers $(A$ and $B$ ) constant, if one of the numbers is increased by a certain amount $(x)$, then the other number must be decreased by the same amount $(x)$. That is,

$$
S=A+B=(A+x)+(B-x) .
$$

I argue that Amber's explanation is based on a model of "compensatory equivalence." That is, if two causal agents act together to produce a result, then the result can be kept unchanged by altering the effect of both the agents in a mutually compensatory fashion. In this case, the "filling-time" is the result that remains unchanged when the values of both the causal agents (i.e., number and speed) are altered in a mutually compensatory way. This is reflected in line 10, when Amber explains that you had to decrease their number, and umm.. the speed.... umm.. you had to increase, to make up for the time...

One could further argue that this explanation is an evidence of the "cancelling" p-prim (diSessa, 1993). diSessa points out that this p-prim is activated in situations in which two opposing forces "try" to achieve mutually exclusive results but happen to cancel each other out. And, "for a situation involving dynamic balancing, canceling justifies lack of result" (diSessa, 1993, p 135). In this case, we believe that the equal and opposite tendencies of the higher number and lower speed of electrons (or vice versa), in terms of their effects on the filling-time, result in a dynamic balance scenario, which in turn activates the "cancelling" p-prim.

\section{David (and Sam) (seventh Grade)}

The following interview took place when David was performing the balancing time activity. I asked David to explain how they were planning to approach the task, and the following conversation ensued:

Excerpt 1

(1) I: so how are you guys working on number 14 ? What is the idea?

(2) David: So we are trying to get the speed.. trying to change the speed.. trying to variate.. kind of variate what the speed is coz we want to make it (pointing to Ts on the Activity Sheet) almost equal or close to 216 isecs, because in question 5, that is what the speed (Ts) is...

(3) I: So are you variating.. like increasing and decreasing the speed?

(4) David: Yeah..

(5) Sam (to David): well 2.6 is going to be too fast

(6) I: so can you tell me if the speed is going to be higher or lower?

(7) Sam: We just got it.. it is 2.4 ..

(8) David: Its (Ts) the exact same

(9) Sam: Yeah.. we were able to get the exact same (Ts) 
(10) David (to me): The speed was higher because the number of electrons that were capable of being able to go in to the positive charge at one time was lower

David's response in line 10 indicates that the situation at hand registered in his mind as one in which electrons are "going into" the battery positive. It indicates a process of simultaneous "entry" of multiple electrons (going into, at one time), which we argue, in David's mind, plays an important role in determining how fast the electron-sink is filling up. David's written explanation quoted below provides a clearer picture of his mental model of the relationship between "filling-time" and the process of simultaneous entry of electrons:

The filling-time is lower when many electrons go in at the same time, so they fill up quickly.

The time is the same if there are more electrons moving with less speed and less electrons but moving faster

Figure 7.6 below is a representation of David's mental model of "filling-time".

Each "Time-event", as indicated in Fig. 7.6, represents a unit of time, during which a certain number of electrons enter the electron-sink. The notion of a timeevent is evidenced in David's statement in line 10 in the above excerpt, where he explicitly mentions that a certain number of electrons "go in at one time." His explanation therefore indicates that the constituents of "filling-time" are a series of these repeated, discrete time-events, each of which involves simultaneous entry of multiple electrons. According to this model, if more electrons are capable of going in "at one time," the filling-time is lower, and vice-versa.

Furthermore, David's written explanation and interview excerpt also indicated that he was able to identify the mutually compensatory role of number and speed of electrons that resulted in conserving the value of filling-time. His interview response (see line 10 in Excerpt 1) indicated that a higher speed can compensate for a lower number of electrons, as it enables more electrons to "go in to the positive charge at one time". And in his written response, he identified that the filling-time is the same if "if there are more electrons moving with less speed, and less electrons but

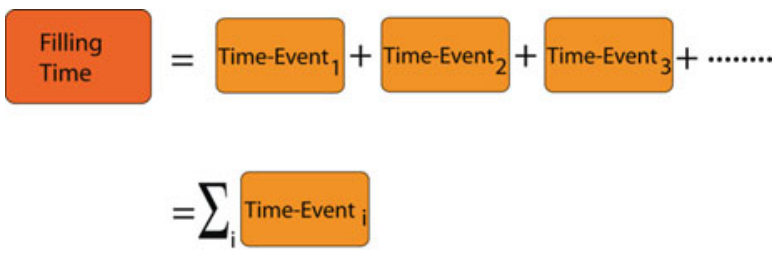

Time-Event $\mathrm{i}=\begin{aligned} & \text { number of electrons going into the sink } \\ & \text { in one unit time }\end{aligned}$

Fig. 7.6 David's mental model of "filling-time" 
moving faster." We therefore believe that David's responses indicate a dynamic balance schema, in which the number and speed of electrons act as opposing influences that result in keeping the value of filling-time unchanged. As discussed earlier in the previous cases, we believe that this is also an evidence of the "canceling" p-prim.

\section{Written Explanations of the "Balancing Filling-Time" Activity}

As indicated in Table 7.1, after performing the "Balancing Filling-time" activity, students were asked to explain why the electron-sink filled up in the same time $(T)$ in both cases. Students' responses to this question were coded into the following types: number-speed complementarity, filling-capacity-based, and speed-based. Sample responses, along with percentages of responses of each type, are shown in Table 7.2.

Responses that included a mutually complementary or compensatory change in both number and speed of electrons were coded as Number-Speed Complementarity. It is notable that responses of the majority of the students in each grade (70\% in fifth grade and $75 \%$ in seventh grade) were of this type. Speed-based responses indicated that the alteration in speed was the reason why the value of time was identical in both cases. Responses of $5 \%$ of students in each grade belonged to this category. Finally, responses that were coded as "Filling-capacity-based" indicated that the filling-time was identical in both cases as the same number of electrons (equal to the fillingcapacity of the electron-sink) came into the battery positive. Fifteen percentage of fifth graders' responses and $10 \%$ of seventh graders' responses belonged to this

Table 7.2 Students' responses-“balancing time" activity

\begin{tabular}{llll}
\hline Type of explanation & Sample response & $\begin{array}{l}\text { \% of students } \\
\text { (fifth grade) }\end{array}$ & $\begin{array}{l}\text { \% of students } \\
\text { (seventh } \\
\text { grade) }\end{array}$ \\
\hline $\begin{array}{l}\text { Number-speed } \\
\text { complementarity }\end{array}$ & $\begin{array}{l}\text { "Speed goes up and number goes } \\
\text { down to keep time same"; } \\
\text { "Number and speed balance each } \\
\text { other out"; } \\
\text { "With less speed and more } \\
\text { electrons, more electrons get in. } \\
\text { But with more speed and less } \\
\text { electrons, the speed pushes more } \\
\text { electrons." }\end{array}$ & 70 \\
Filling-capacity-based & $\begin{array}{l}\text { "Same amount of electrons come } \\
\text { in in both cases"; } \\
\text { "Because same number of } \\
\text { electrons come in and fill up the } \\
\text { sink" }\end{array}$ & 15 & 10 \\
"speed went up"; \\
"speed was higher" & 5 & 5 \\
\hline No response & 10 & 15 \\
\hline
\end{tabular}


category. Ten percentage of students in fifth grade and $15 \%$ of students in seventh grade did not respond to the question.

\section{From "Filling-Time" to Electric Current}

This section focuses on how fifth and seventh graders in the electron-sink group related their understanding of "filling-time" to the notion of electric current. The data for this section come from students' written responses in the activity sheet, pertaining to activity $\mathrm{D}$ in Table 7.1 After completing the activity of balancing the value of filling-time discussed in the previous section, students in the electron-sink group were asked to perform the following activity:

Together, the wire and the battery terminals shown in the computer model are called an electric circuit. Electric current in any circuit can be understood as how fast the electronsink (i.e., the battery positive) is filling up. Based on all the activities you have done so far, how would you measure electric current (i.e., how fast the electron-sink is filling up) in the circuit shown in the computer model?

Students' responses were coded as follows: number based, speed based, time based, number-and-speed based, number-and-time based. Figure 7.7 shows the percentage of responses of each type of students in both fifth and seventh grades, and Table 7.3 shows sample responses pertaining to each type.

Responses were coded in terms of what model attributes students indicated had to be measured in order to measure electric current in the circuit shown in the model. Number-based responses typically indicated "number of electrons" as the only attribute that would have to be measured in order to measure electric current.

\section{Measuring Current}

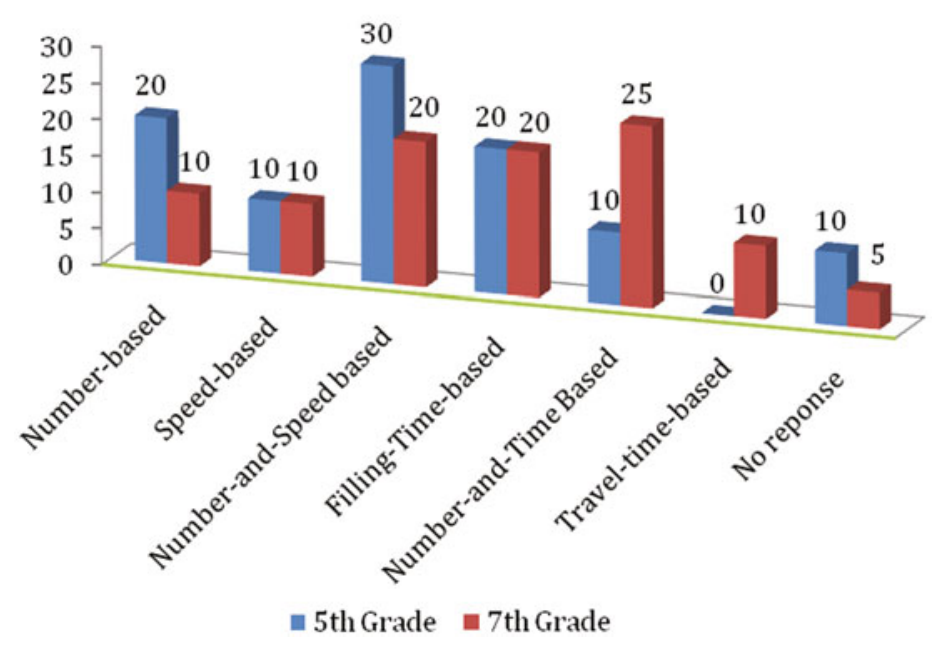

Fig. 7.7 Percentage of different types of students' reponses to the "measuring current" activity 
Table 7.3 Students' responses_- “measuring current" activity

\begin{tabular}{|c|c|c|c|}
\hline Type of responses & Sample responses & $\begin{array}{l}\% \text { of students } \\
\text { (fifth grade) }\end{array}$ & $\begin{array}{l}\% \text { of students } \\
\text { (seventh } \\
\text { grade) }\end{array}$ \\
\hline Number-based & $\begin{array}{l}\text { "I will count how many electrons } \\
\text { are there in the circuit" } \\
\text { "If there are more electrons there } \\
\text { will be more current" }\end{array}$ & 20 & 10 \\
\hline Speed-based & $\begin{array}{l}\text { "You can measure current by the } \\
\text { speed slider" } \\
\text { "speed of electrons" }\end{array}$ & 10 & 10 \\
\hline $\begin{array}{l}\text { Number-and-speed } \\
\text { based }\end{array}$ & $\begin{array}{l}\text { "I would count how many there are } \\
\text { and how fast they are moving" } \\
\text { "Both number and speed of } \\
\text { electrons" }\end{array}$ & 30 & 20 \\
\hline Filling-time based & $\begin{array}{l}\text { "how long it takes to fill the sink" } \\
\text { "Count } T \text { " }\end{array}$ & 20 & 20 \\
\hline $\begin{array}{l}\text { Number-and-time } \\
\text { based }\end{array}$ & $\begin{array}{l}\text { "I would measure how many are } \\
\text { coming in and in what time" } \\
\text { "number and } T "\end{array}$ & 10 & 10 \\
\hline Travel time based & $\begin{array}{l}\text { "I would measure how long the } \\
\text { ticks (electrons) take to reach } \\
\text { the positive" }\end{array}$ & 0 & 10 \\
\hline No response & - & 10 & 5 \\
\hline
\end{tabular}

Twenty percentage of fifth graders and $10 \%$ of seventh graders' responses were of this type. Similarly, responses that were coded as Speed-based typically indicated the "speed of electrons" or "how fast electrons are going" as the only attribute to be measured, and responses of $10 \%$ of students in both fifth and seventh grades were of this type. Filling-time-based responses indicated that electric current could be measured by "counting" or "measuring" the value of $T$ (or "how long it takes to fill the sink). Twenty percentage of students' responses in each grade were of this category.

Note that $30 \%$ of fifth graders and $20 \%$ of seventh graders mentioned both number and speed of electrons as attributes that would have to be measured in order to measure electric current. These responses were coded as number-and-speed based. Students whose responses were coded as Number-and-time based indicated that they would measure electric current in the circuit by calculating how many electrons are inside the sink and dividing it by the time. This suggests that some students were constructing an understanding of electric current as a particular ratio of number of electrons in the sink and time. $10 \%$ of fifth graders' and $25 \%$ of seventh graders' responses were of this type.

Students whose responses were coded as travel time based, indicated that they would calculate how much time the electrons take to reach the battery positive in order to measure electric current. Only $10 \%$ of seventh graders' responses were of this type.

These responses indicate that even when more than $80 \%$ of the students in each class successfully performed the "Balancing time" activity, only $30 \%$ of fiftth 
graders and $20 \%$ of seventh graders indicated that electric current could be measured by observing or calculating both the number and speed of electrons. One possible explanation is as follows: factors or attributes that affect electric current, in the students' minds, are not always isomorphic to the factors or attributes that need to be measured in order to measure electric current.

Note that the total percentage of students whose responses were either coded as "Filling-time based" or "Number and speed based" or "number and time based" was $60 \%$ in fifth grade and $65 \%$ in seventh grade. It is noteworthy that these responses focus on model attributes (or variables) that either explicitly involve number and speed of electrons, or are directly affected by both of them. Therefore, this indicates that majority of the students were able to develop an understanding of electric current based on the effects of both the number and the speed of electrons.

\section{Between-Group Quantitative Comparisons of Post-explanations of "Balancing Current"}

Note that after their interaction with the models, participants in both the groups were asked to predict whether electric current would be higher if twice as many electrons moved twice as slowly and select an explanation from a list to justify their selection. Specifically, they were asked to answer the following question:

$Q$ 1: In Wire A, there are 400 electrons and the speed of the electrons is 40 units. In another wire (Wire B), there are 800 electrons and the speed is 20 units. Which of the following do you think is true:

(a) Electric current in Wire $\mathrm{A}$ is more than in Wire $\mathrm{B}$

(b) Electric current in Wire B is more than in Wire A

(c) Electric current is same in both Wire A and Wire B.

$Q$ 2: Now, from the list below, select the option(s) that describe(s) the reasons for your choice (NOTE: You CAN select more than one option)

(a) Current is higher in Wire B because there are more electrons in Wire B

(b) Current is lower in Wire B because the speed of electrons is lower in Wire B

(c) Current is lower in Wire A because there are less electrons in Wire A

(d) Current is higher in Wire A because the speed of electrons is higher in Wire A

(e) In Wire B, there are more electrons with less speed and in Wire A, less electrons with more speed. So they have equal current."

Our analysis reveals that majority of the fifth- and seventh-grade participants in the pilot group were unable to predict (and explain) the correct behavior. In their responses to Q 2, 45\% of the students in fifth grade and $50 \%$ of students in seventh grade selected either option (a) or (c), indicating the current would be higher when there are more electrons (or lower when there are fewer electrons). Fifty five percent of the students in fifth grade and $44 \%$ of seventh graders indicated that current would be higher when the electrons are moving faster (or, lower when the electrons are moving slower). Only 5\% of the seventh graders in the pilot group, and 5\% of the 
students in fifth grade selected option (e), indicating that the number and speed of electrons when altered together in a complementary fashion, that ensures the constancy of electric current. On the other hand, $90 \%$ of the 12 th graders were able to make the correct prediction and identify the compensatory relationship between number and speed of electrons as the cause.

In contrast, $92 \%$ of fifth grade and $94 \%$ of seventh-grade students in the Electron-sink group identified option (e) to indicate their reasoning. This indicates that students were able to identify compensatory effects of number and speed of electrons on electric current. These results are shown in Figs. 7.8 and 7.9.

Responses of fifth and seventh graders in the electron-sink group were compared to that of 12 th graders in the pilot group using one-way $\operatorname{ANOVA}(\mathrm{F}(2,58)=0.5241$

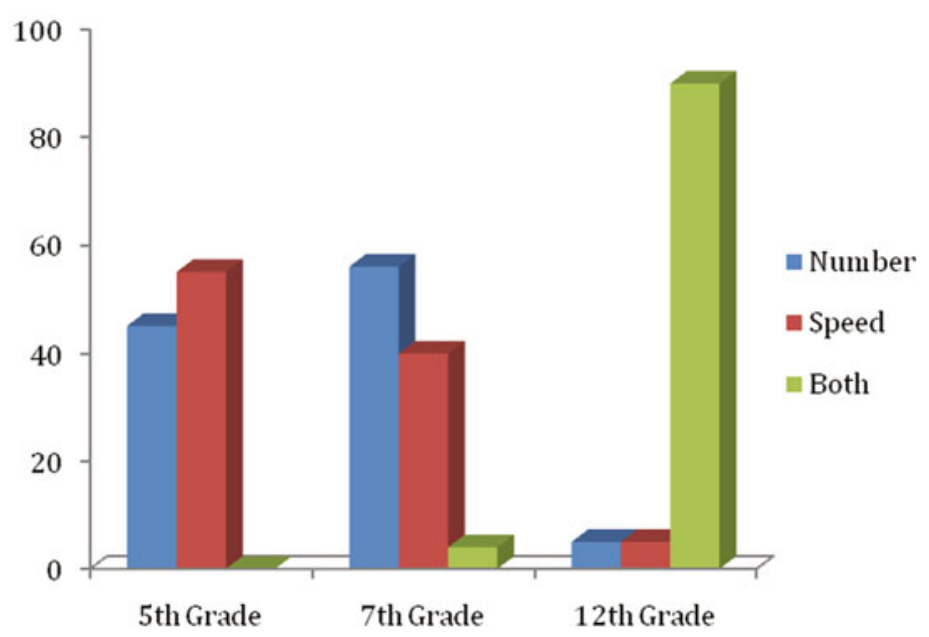

Fig. 7.8 "Balancing" current: A comparison of pilot group and 12th grade responses

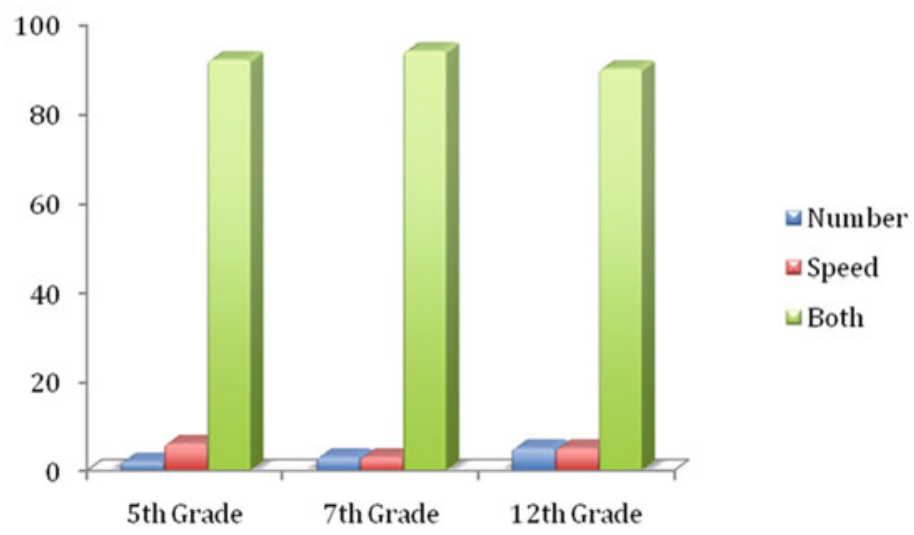

Fig. 7.9 "Balancing" current: A comparison of electron-sink group and 12th grade responses 
$(p>0.5)$ ), indicating that there is no significant difference in mean performance between these groups. In other words, the performance of fifth and seveth graders in the electron-sink group is indeed comparable to that of the 12th graders in the pilot group.

\section{Discussion}

From the epistemological perspective, the central goal of this chapter was to highlight the epistemic significance of a particular design strategy_-framing electrical conduction as a process of accumulation of charges inside the battery positive terminal, using a multi-agent-based approach. Overall, the results reported here suggest that this design strategy was indeed successful, as indicated by the explanations of 5th and 7th graders in the electron-sink group reported in the section "Findings".

Three points are noteworthy in this respect. The first point concerns our proposed theoretical model for analyzing misconceptions in electricity, where we argued that the same naïve knowledge resources that have been found to be responsible for generating misconceptions, can be bootstrapped at the microscopic level to engender a correct and deep understanding of the same phenomena. This corroborates our claim that misconceptions in electricity can indeed be understood as behavioral evidences of "slippage between levels" (Sengupta \& Wilensky, 2009). For example, earlier in this chapter, we have pointed out that several researchers have observed that novice students often use the "source-sink" model in reasoning about the behavior of electric current in a circuit, and this leads to erroneous predictions that have been noted as "misconceptions". Note that as Reiner et al. (2000) points out, typically, such responses are limited to the macroscopic-level descriptions of the relevant phenomenon. The analysis presented in this chapter suggests that the same source-sink model, when appropriated to describe the behavior of microscopic level objects (agents) such as electrons (instead of electric current, the macro- or aggregate-level phenomenon) can indeed act as a productive epistemic resource for students. It enables them to focus on how fast the sink is filling up, and thereby develop an understanding of the conservation of the "filling-time" (and hence, electric current), based on simultaneous and compensatory changes in the values of number and speed of electrons. The learners are thus able to construct conceptual links between the micro-level agents and their attributes on one hand, and the macrolevel phenomena on the other. This was evident in both the interview responses of the students (which highlight their emergent mental models), as well as their written responses. This is particularly significant, as Eylon and Ganiel (1990) argued that the missing macro-micro link is at the root of students' difficulties in the domain of electromagnetism.

Furthermore, this chapter shows that our design strategy enabled learners as young as fifth graders to develop an understanding of electric current as a "rate" of electron flow by bootstrapping their intuitive knowledge of "building up" (Thompson, 1994). This leads us to our second point: The ability to bootstrap learners' repertoire of intuitive knowledge is a particularly important affordance of 
multi-agent-based models, and this strategy has been shown to be effective in alleviating misconceptions of novice learners across several domains: chemistry (Stieff \& Wilensky, 2003; Levy \& Wilensky, 2005), biology (Reisman \& Wilensky, 2006), materials science (Blikstein \& Wilensky, 2009), physics (Sengupta \& Wilensky, 2009, under review; Wilensky, 2003), etc. In this perspective, misconceptions are not resultant from naïve intuitive knowledge that is incompatible with expert ontology; rather, as our work shows, a deep understanding can indeed emerge through bootstrapping naïve intuitive knowledge.

Our third point relates to what Wilensky (2006) and Wilensky and Papert (in progress) termed "restructurations." Wilensky and colleagues defined "structuration" as the way (i.e., the representational infrastructure) in which knowledge is encoded in a discipline. Re-structuration means altering this encoding by changing the representational infrastructure. Wilensky and colleagues argued that when the representational infrastructure in a domain is altered in such a way that it aligns with intuitive knowledge structures of novices, it leverages the "learnability" of the domain. An example of restructuration is the representational system of multi-agentbased models - specifically the NetLogo platform — which enabled us to create a suite of models that are well aligned with naïve intuition, and allowed us to implement our specific design strategy of framing electric current as a process of accumulation. The results reported here enabled much younger students (fifth graders) to develop a deep understanding of electric current. Wilensky (2003) provides another example in which emergent multi-agent computational (NetLogo based) representations enabled middle school students to learn statistical mechanics, which is traditionally taught using equation-based representations in advanced physics courses (college level and beyond). Other examples can be found in Blikstein and Wilensky (2006), where the authors show how NetLogo-based representations can enable novices to engender an expert-like understanding of key concepts in materials science. Even earlier examples of restructurations that extend beyond physics include Papert and his colleagues' research on fifth graders learning fractions using Logo (Harel \& Papert, 1991) and Wilensky and Reisman's (1998 (2006)) research on restucturating biology using NetLogo models, etc. Each of these studies showed that bootstrapping novices' agent level instuitions can leverage learnability in the domains of physics, mathematics, materials science, and biology. In other words, the new structurations (i.e., computational representations embodied in the designed learning environments) were much more closely aligned with the novices' intuitive knowledge than the corresponding traditional structurations (e.g., equations and other mathematical formalisms) that are difficult for these novices to understand.

Finally, it is noteworthy that our work presented here raises an interesting question: if fifth graders can now learn more advanced content as shown in this chapter, then "what happens next"? That is, what happens when these students advance to higher grades (6th-12th)? Answering this question requires an inherently developmental perspective, as our colleagues Lehrer and Schauble (2006) have argued for. The present chapter focuses on how the same model can be successfully adapted for 12 th and 5th graders through reframing the same emergent phenomenon (flow vs. accumulation), thus lowering the learning threshold. Note that on the "high-ceiling" 
side of the spectrum, although 12th graders in this study performed additional activities such as conducting experiments with the variables in the model, this was not discussed in this chapter; furthermore, we consider this to be only a preliminary exploration of the "high-ceiling" side of this spectrum. Answering this important question is an important component of our current research agenda, and we believe that developing a longer term learning progression will undoubtedly have significant implications for both researchers in Learning Sciences and for the National Science Education Standards.

\section{References}

Abrahamson, D., Janusz, R. M., \& Wilensky, U. (2006). There once was a 9-Block-A middleschool design for probability and statistics. Journal of Statistics Education, 8, 1.

Abrahamson, D., \& Wilensky, U. (2005). Understanding chance: From student voice to learning supports in a design experiment in the domain of probability. In G. M. Lloyd, M. Wilson, J. L. M. Wilkins, \& S. L. Behm, (Eds.), Proceedings of the twenty seventh annual meeting of the North American chapter of the international group for the psychology of mathematics education (pp. 1-7). Roanoke, VA: Virginia Tech University.

American Association for the Advancement of Science. (1993). Benchmarks for scientific literacy. New York: Oxford University Press.

Ashcroft, J. N., \& Mermin, D. (1976). Solid state physics. Holt: Rinegart and Winston.

Bagno, E., \& Eylon, B.-S. (1997). From problem solving to a knowledge structure: An example from the domain of electromagnetism. American Journal of Physics, 65, 726.

Bagno, E., Eylon, B.-S., \& Ganiel, U. (2000). From fragmented knowledge to a knowledge structure: Linking the domains of mechanics and electromagnetism. Physics Education Research Supplement; American Journal of Physics, 68(S2), S16-S26.

Belcher, J. W., \& Olbert, S. (2003). Field line motion in classical electromagnetism. American Journal of Physics, 71, 220.

Blikstein, P., \& Wilensky, U. (2006). A case study of multi-agent-based simulation in undergraduate materials science education. Paper presented at the Annual Conference of the American Society for Engineering Education, Chicago, IL, June 18-21.

Blikstein, P., \& Wilensky, U. (June 2008). Implementing agent-based modeling in the classroomlessons from empirical studies in undergraduate engineering education. In G. Kanselaar, J. van Merinboer, P. Kirschner, \& T. de Jong (Eds.), Proceedings of the international conference of the learning sciences (ICLS). (pp. 266-267). Utrecht: ICLS.

Blikstein, P., \& Wilensky, U. (2009). An atom is known by the company it keeps: A constructionist learning environment for materials science using multi-agent simulation. International Journal of Computers for Mathematical Learning, 14(1), 81-119.

Centola, D., McKenzie, E., \& Wilensky, U. (2000). Survival of the groupiest: facilitating students' understanding of multi-level evolution through multi-agent modeling-the EACH project, The 4th international conference on complex systems. Nashua, NH: New England Complex Systems Institute.

Chabay, R. W., \& Sherwood, B. A. (2000). Matter \& Interactions I: Modern Mechanics and Matter \& Interactions II: Electric \& Magnetic Interactions. New York: Wiley.

Chi, M. T. H. (2005). Common sense conceptions of emergent processes: Why some misconceptions are robust. Journal of the Learning Sciences, 14, 161-199.

Chi, M. T. H., Feltovich, P., \& Glaser, R. (1981). Categorization and representation of physics problems by experts and novices. Cognitive Science, 5, 121.

Chi, M. T. H., Slotta, J. D., \& de Leeuw, N. (1994). From things to processes: A theory of conceptual change for learning science concepts. Learning and Instruction, 4, 27-43. 
Cohen, R., Eylon, B. S., \& Ganiel, U. (1983). Potential difference and current in simple electric circuits: A study of students' concepts. American Journal of Physics, 51, 407-412.

diSessa, A. (1993). Towards an epistemology of physics. Cognition and Instruction, 10, 105-225.

diSessa, A. A., \& Sherin, B. L. (1998). What changes in conceptual change? International Journal of Science Education, 20(10), 1155-1191.

Drude, P. (1900). Zur Elektronentheorie der Metalle. Annalen der Physik, 1:566-613.

Duit, R. (1991). On the role of analogies and metaphors in learning science. Science Education, 75, 649-672.

Dupin, J., \& Johsua, S. (1987). Conceptions of French pupils concerning electric circuits: Structure and evolution. Journal of Research in Science Teaching, 24, 791-806.

Einstein, A. (1950). Out of my later years. New York: Philosophical Library.

Eylon, B. -S., \& Ganiel, U. (1990). Macro-micro relationships: The missing link between electrostatics and electrodynamics in student reasoning. International Journal of Science Education, 12(1), 79-94.

Fredericksen, J., \& White, B. (1992). Mental models and understanding: A problem for science education. In E. Scanlon, \& T. O'Shea, (Eds.), New directions in educational technology. (pp. 211-226). New York: Springer.

Frederiksen, J., \& White, B. (1988). Teaching and learning generic modeling and reasoning skills. Journal of Interactive Learning Environments, 5, 33-51.

Frederiksen, J., White, B., \& Gutwill, J. (1999). Dynamic mental models in learning science: The importance of constructing derivational linkages among models. Journal of Research in Science Teaching, 36(7), 806-836.

Forbus, K., \& Gentner, D. (1986). Learning physical domains: towards a new theoretical framework. In R. Michalski, J. Carbonell, \& T. Mitchell (Eds.), Machine Learning: An Artificial Intelligence Approach (Vol. 2), 311-348. Tioga press.

Gentner, D., \& Gentner, D. R. (1983). Flowing waters or teeming crowds: Mental models of electricity. In D. Gentner, \& A. L. Stevens, (Eds.), Mental models (pp. 99-129), Lawrence Erlbaum Associates, New Jersey.

Goldstone, R., \& Wilensky, U. (2008). Promoting transfer by grounding complex systems principles. Journal of the Learning Sciences, 17(4), 465-516.

Haertel, H. (1987). A qualitative approach to electricity. Report No. IRL87-0011I, Xerox PARC, Palo Alto, CA.

Hammer, D. (1996). Misconceptions or p-prims: How may alternative perspectives of cognitive structure influence instructional perceptions and intentions? Journal of the Learning Sciences, 5(2), 97-127.

Hardiman, P. T., Well, A. D., \& Pollatsek, A. (1984). The usefulness of a balance model in understanding the mean. Journal of Educational Psychology, 7(6), 792-801.

Hartel, H. (1982). The electric circuit as a system: A new approach. European Journal of Science Education, 4, 45-55.

Inhelder, B., \& Piaget, J. (1958). The growth of logical thinking from childhood to adolescence. New York: Basic.

Jackson, S. (1965). The growth of logical thinking in normal and subnormal children. British Journal of Educational Psychology, 3(5), 255-258.

Joshua, S., \& Dupin, J. J. (1987). Taking into account student conceptions in instructional strategy: An example in physics. Cognition and Instruction, 4, 117-135.

Kaput, J. \& West, M. (1994). Missing-value proportional reasoning problems: factors affecting informal reasoning patterns. In G. Harel, \& J. Confrey (Eds.), The development of multiplicative reasoning in the learning of mathematics. (pp. 235-287). Albany, NY: State University of New York Press.

Lasser, C., \& Omohundro, S. M. (1986). The essential starlisp manual. Waltham, MA: Thinking Machines Corporation.

Lee, V. R., \& Sherin, B. (2006). Beyond transparency: How students make representations meaningful. Proceedings of the Seventh International Conference of the Learning Sciences, Bloomington, IN, 397-403. 
Lehrer, R., \& Schauble, L. (2006). Scientific thinking and science literacy. In W. Damon, R. Lerner, K. A. Renninger, \& I. E. Sigel (Eds.), Handbook of child psychology, 6th Ed., Vol. 4: Child psychology in practice (pp. 153-196). Hoboken, NJ: Wiley.

Levy, S. T., Kim, H., \& Wilensky, U. (2004). Connected Chemistry-A study of secondary students using agent-based models to learn chemistry. Paper presented at the annual meeting of the American Educational Research Association, San Diego, CA, April 12-16.

Levy, S. T., \& Wilensky, U. (2005). Students' patterns in exploring NetLogo models, embedded in the Connected Chemistry curriculum. In J. Gobert (Chair) \& J. Pellegrino (Discussant) (Eds.), Logging students' learning in complex domains: Empirical considerations and technological solutions. Paper presented at the annual meeting of the American Educational Research Association, Montreal, QC, Canada, April 11-15.

Levy, S. T., \& Wilensky, U. (2008). Inventing a "mid-level” to make ends meet: Reasoning through the levels of complexity. Cognition and Instruction, 26(1), 1-47.

Levy, S. T., \& Wilensky, U. (2009). Crossing levels and representations: The Connected Chemistry (CC1) curriculum. Journal of Science Education and Technology, 18(3), 224-242.

Lovell, K. (1961). A follow-up study of Inhelder and Piaget's "The growth of logical thinking." British Journal of Psychology, 52, 143-153.

Metz, K. E. (2004). Children's understanding of scientific inquiry: Their conceptualization of uncertainty in investigations of their own design. Cognition and Instruction, 2(22), 219-291.

National Academies Press. (1996). National science education standards. Retrieved March 30, 2010, from http://www.nap.edu/catalog.php?record_id $=4962$

Niederrer, H., \& Goldberg, F. (1996). Learning processes in electric circuits. St. Louis: Presented at NARST.

Papert, S. (1980). Mindstorms: Children, computers, and powerful ideas. New York: Basic Books.

Papert, S. (1991). Situating constructionism. In I. Harel, \& S. Papert (Eds.), Constructionism. Norwood, NJ: Ablex Publishing Corporation.

Pfund, H., \& Duit, R. (1998). Bibliography: Students' alternative frameworks and science education. Kiel, Alemania: IPN.

Rand, W., Novak, M., \& Wilensky, U. (2007). BEAGLE curriculum. Evanston, IL: Center for Connected Learning and Computer-Based Modeling, Northwestern University.

Reiner, M., Slotta, J. D., Chi, T. H., \& Resnick, L. B. (2000). Naïve physics reasoning: A commitment to substance-based conceptions. Cognition and Instruction, 18(1), 1-34.

Resnick, M., \& Wilensky, U. (1998). Diving into complexity: Developing probabilistic decentralized thinking through role-playing activities. Journal of Learning Sciences, 7(2)

Roschelle, J. (1991). Students' construction of qualitative physics knowledge: Learning about velocity and acceleration in a computer microworld. Unpublished doctoral dissertation, University of California, Berkeley.

Sengupta, P. (2009). Designing across ages: Multi-agent based models and learning electricity. Unpublished doctoral dissertation. Northwestern University, USA.

Sengupta, P., \& Wilensky, U. (2005). N.I.E.L.S: An emergent multi-agent based modeling environment for learning physics. Proceedings of the agent-based systems for human learning workshop, 4th international joint conference on Autonomous Agents and Multiagent Systems (AAMAS 2005), Utrecht, Netherlands.

Sengupta, P., \& Wilensky, U. (2006) NIELS: An agent-based modeling environment for learning electromagnetism. Paper presented at the annual meeting of the American Educational Research Association, San Francisco, CA.

Sengupta, P., \& Wilensky, U. (2008a). Designing across ages: On the low-threshold-high-ceiling nature of netlogo based learning environments. Paper presented at the annual meeting of the American Educational Research Association (AERA 2008), New York.

Sengupta, P., \& Wilensky, U. (2008b). On the learnability of electricity as a complex system. In G. Kanselaar, J. van Merri'nboer, P. Kirschner, \& T. de Jong (Eds.), Proceedings of the Eighth International Conference of the Learning Sciences-ICLS 2008 (Vol. 3, pp. 122-124). Utrecht, The Netherlands: ICLS. 
Sengupta, P., \& Wilensky, U. (2009). Learning electricity with NIELS: Thinking with electrons and thinking in levels. International Journal of Computers for Mathematical Learning, 14(1), $21-50$.

Smith, J. P., diSessa, A. A., \& Roschelle, J. (1993). Misconceptions reconceived: A constructivist analysis of knowledge in transition. Journal of the Learning Sciences, 3(2), 115-163.

Siegler, R. S. (1976). Three aspects of cognitive development. Cognitive Psychology, 8, 481-520.

Siegler, R. S. (1978). The origins of scientific reasoning. In R. S. Siegler (Ed.), Children's thinking: What develops? (pp. 109-151). Hillsdale, NJ: Lawrence Erlbaum Associates.

Siegler, R. S., \& Klahr, D. (1982). Why do children learn? The relationship between existing knowledge and the acquisition of new knowledge. In R. Glaser (Ed.), Advances in instructional psychology (Vol. 2, pp. 121-211). Hillsdale, NJ: Lawrence Erlbaum Associates.

Simon, H. A. (1969). The sciences of the artificial. Cambridge, MA: The MIT Press.

Slotta, J. D., \& Chi, M. T. H. (2006). The impact of ontology training on conceptual change: Helping students understand the challenging topics in science. Cognition and Instruction, 24(2), 261-289.

Stieff, M., \& Wilensky, U. (2003). Connected chemistry-incorporating interactive simulations into the chemistry classroom. Journal of Science Education and Technology, 12(3), 285-302.

Thompson, P. W. (1994). The development of the concept of speed and its relationship to concepts of rate. In G. Harel \& J. Confrey (Eds.), The development of multiplicative reasoning in the learning of mathematics (pp. 179-234). Albany, NY: SUNY Press.

White, B., \& Frederiksen, J. (1998). Inquiry, modeling, and metacognition: making science accessible to all students. Cognition and Instruction, 16(1), 3-118.

White, B., Frederiksen, J., \& Spoehr, K. (1993). Conceptual models for understanding the behavior of electrical circuits. In M. Caillot (Ed.), Learning electricity and electronics with advanced educational technology (pp. 77-95). New York: Springer.

Wilensky, U. (1991). Abstract meditations on the concrete and concrete implications for mathematics education. In I. Harel, \& S. Papert (Eds.), Constructionism (pp. 193-203). Norwood, MA: Ablex.

Wilensky, U. (1993). Connected mathematics: Building concrete relationships with mathematical knowledge. Unpublished doctoral dissertation Cambridge, MA: MIT.

Wilensky, U. (1999a). NetLogo. Center for connected learning and computer-based modeling. Northwestern University, Evanston, IL. http://ccl.northwestern.edu/netlogo. Accessed 1 Jul 2010.

Wilensky, U. (1999b). GasLab: An extensible modeling toolkit for exploring micro-and macroviews of gases. In N. Roberts, W. Feurzeig, \& B. Hunter, (Eds.), Computer modeling and simulation in science education (pp. 151-178). Berlin: Springer.

Wilensky, U. (2001). Modeling nature's emergent patterns with multi-agent languages proceedings of EuroLogo 2001. Austria: Linz.

Wilensky, U. (2003). Statistical mechanics for secondary school: The GasLab modelling toolkit. International Journal of Computers for Mathematical Learning, 8(1), 1-41. (special issue on agent-based modeling)

Wilensky, U. (April, 2006). Complex systems and restructuration of scientific disciplines: Implications for learning, analysis of social systems, and educational policy. In J. Kolodner (Chair), C. Bereiter (Discussant), \& J. D. Bransford (Discussant), Complex systems, learning, and education: Conceptual principles, methodology. Paper presented at the Annual Meeting of the American Educational Researchers' Association.

Wilensky, U., Hazzard, E., \& Longenecker, S. (2000). A bale of turtles: A case study of a middle school science class studying complexity using StarLogoT. Paper presented at the meeting of the Spencer Foundation, New York, October 11-13.

Wilensky, U., \& Papert, S. (in preparation). Restructurations: Reformulations of knowledge disciplines through new representational forms. (Manuscript in preparation)

Wilensky, U., \& Reisman, K. (2006). Thinking like a wolf, a sheep or a firefly: Learning biology through constructing and testing computational theories-an embodied modeling approach. Cognition and Instruction, 24(2), 171-209. 
Wilensky, U., \& Resnick, M. (1995). New thinking for new sciences: Constructionist approaches for exploring complexity. Paper presented at the annual meeting of the American Educational Research Association, San Francisco, CA.

Wilensky, U., \& Resnick, M. (1999). Thinking in levels: A dynamic systems perspective to making sense of the world. Journal of Science Education and Technology, 8(1).

Wilensky, U., Papert, S., Sherin, B., diSessa, A., Kay, A., \& Turkle, S. (2005). Center for learning and computation-based knowledge (CLiCK). Proposal to the National Science FoundationScience of Learning Center. Unpublished manuscript.

\section{NetLogo Models References}

Sengupta, P., \& Wilensky, U. (2008c). NetLogo Electron Sink model. Center for Connected Learning and Computer-Based Modeling, Northwestern University, Evanston, IL http://ccl.northwestern.edu/netlogo/models/Electronsink. Accessed $1 \mathrm{Jul} 2010$.

Sengupta, P., \& Wilensky, U. (2008d). NetLogo Current in a Wire model. Center for Connected Learning and Computer-Based Modeling, Northwestern University, Evanston, IL http://ccl.northwestern.edu/netlogo/models/Currentinawire. Accessed 1 Jul 2010. 